\title{
Morphology and Mechanical Property of Nylon 6 Fibers in the Flags Exposed on the Route between Syowa Station and Dome Fuji in the Antarctic
}

\author{
Tsumuko OKuno, ${ }^{1}$ Yumiko NAKAnO, ${ }^{1}$ Kyoko Yoshida, ${ }^{3}$ Kotaro YoKoYama, ${ }^{2}$ \\ Maki Hamaguchi, ${ }^{1}$ Keiko YANO, ${ }^{1}$ and Masaru MATSUO ${ }^{3, \dagger}$ \\ ${ }^{1}$ Human Environmental Sciences, Faculty of Human Environmental Sciences, Mukogawa Women's University, \\ Ikebiraki-cho, Nishinomiya 663-8558, Japan \\ ${ }^{2}$ Laboratory of Agro-meteorology Hokuriku Research Center NARC, NARO, Inada, Joetsu 943-0193, Japan \\ ${ }^{3}$ Textile and Apparel Science, Faculty of Human Life and Environment, Nara Women's University, \\ Kitauoya Nishi-machi, Nara 630-8263, Japan
}

(Received August 27, 2004; Accepted December 28, 2004; Published March 15, 2005)

\begin{abstract}
Degradation of fibers in the flags as well as color fading of the flags exposed in the Antarctic was investigated as one of indirect methods to take care of health for a number of scientists who study scientific works in out-door during the summer season. Because, it is anxious that the disruption of an ozone layer by freon-gas causes serious health impediments such as the occurrence of skin cancer and the denaturation of a gene, which endangers the life of human.

The flags were set on the route between Syowa Station and Dome Fuji in the Antarctic for one year from the beginning of December 1994 to the end of November 1995. The original fibers with a circular cross section showed flat and smooth surface, while the fibers within the flag exposed on the route showed a weave-like shape by the disappearance of the skin parts. Such violent disruption was not observed for the flags exposed under mild weather in Japan. Because the average irradiation of an ultraviolet ray at the Antarctic as reported is about twice as that at Nishinomiya City observed as an example of mild weather in Japan. [DOI 10.1295/polymj.37.169]

KEY WORDS Degradation of Fibers / Color Fading of the Flag / The Antarctic / Disappearance of the Skin Part /
\end{abstract}

In spite of a number of reports ${ }^{1-11}$ concerning the decrease in mechanical properties of fibers by sunlight exposure, ultraviolet ray irradiation, biodegradation and so on, few reports among them are focused on environmental pollution of the earth. Of course, these studies have been mainly carried out under the mild climate but not under severe climate such as north and south polar zones and Himalayas. Since 1957, a number of investigations for Antarctic zone, which had been considered as unknown continent, have been carried out by a number of scientists in the world. The investigations on many viewpoints of scientific fields become more pronounced year by year, and recent newspapers in the world tend to warn that the melt of ice in Antarctic brings drastic increase in the sea level near future. To pursue many detailed investigations in the Antarctic, it is important to take care of health of scientists who engage the investigations in out-door during the summer season. Despite the warning of the scientists through newspapers, it is well known that modern utilitarian development of industries may causes serious pollution problems in the world. Especially, the disruption of an ozone layer by freon-gas causes serious health impediment such as the occurrence of skin cancer and the denaturation of a gene, which endangers health of human. ${ }^{12-20}$

This paper is concerned with studies on the degradation of thickness of fibers in the flags as well as color fading of the flags exposed by sunshine in the Antarctic for one year. This work was carried out to speculate the influence on human health by the violent irradiation of an ultraviolet ray associated with the disruption of an ozone layer in south polar zone, based on the degradation of flags.

The route flags with red color were set by the staffs of Wintering Party of the 35th Japanese Antarctic Research Expedition for one year from 1994 to 1995 and some of the flags as test specimens, could be carried back to our group, since one of authors, Yokoyama, was a leader of the Japanese Wintering Party. The flags woven by nylon 6 fibers were set as grand marks on a route between Syowa Station and Dome Fuji. The degradation of nylon 6 fibers exposed by ultraviolet ray was estimated in relation to the disruption of the ozone layer as well as multiplex reflection of sunshine from a surface characterizing the circumstance of Antarctic. 


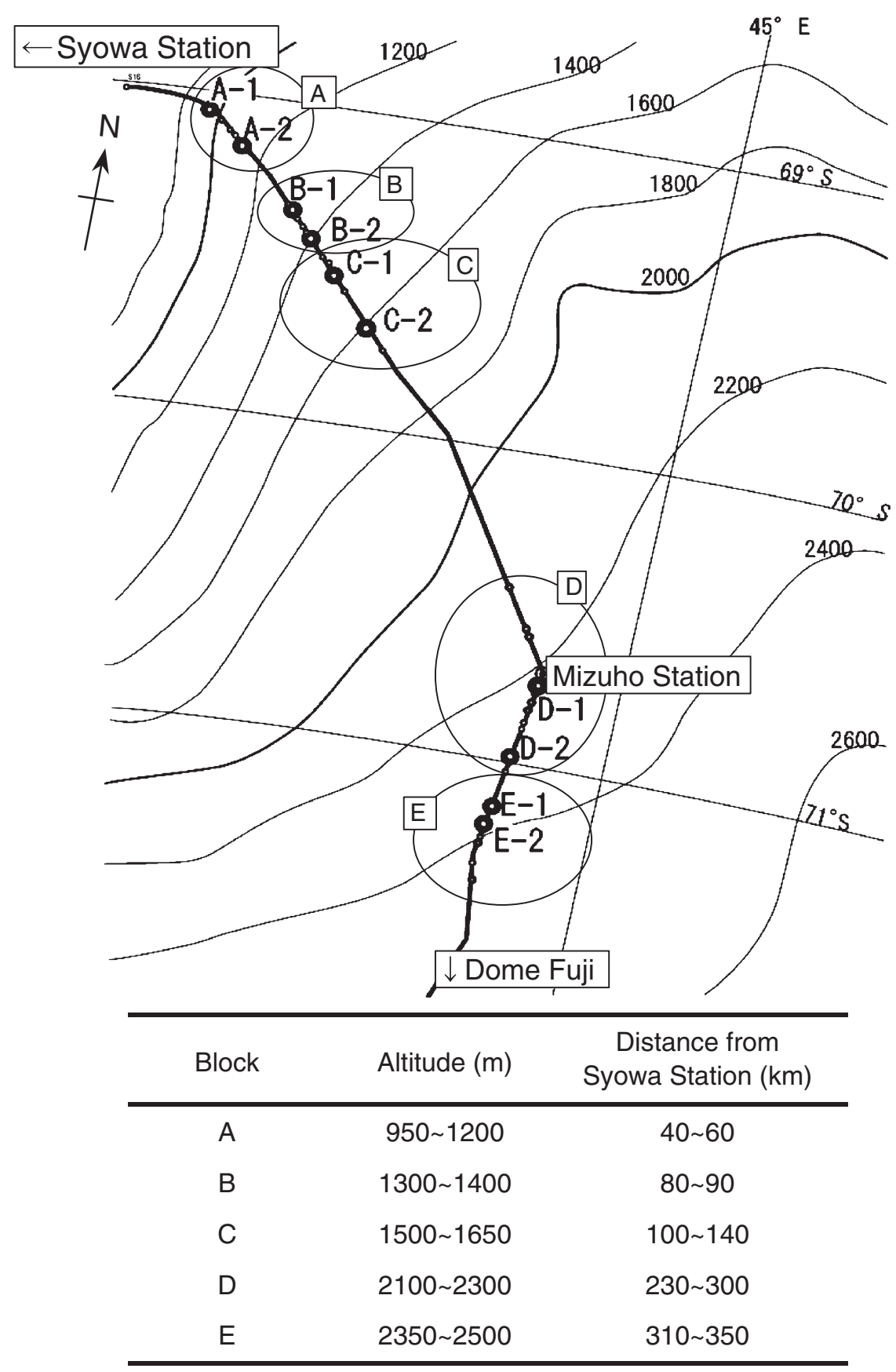

Figure 1. Route-map from the Syowa Station to Dome Fuji.

\section{EXPERIMENTAL}

The flags set on the route between Syowa Station and Dome Fuji in the Antarctic for one year from the beginning of December 1994 to the end of November 1995. Figure 1 shows the route between Syowa Station and Dome Fuji and the setting places of the flags on the route are represented as the open circles on the route. The flags were arranged as the navigation at $c a$. $1 \mathrm{~km}$ intervals on the route. In this paper, the route was divided into five blocks, A-E, in accordance with sea level from $c a .1000$ to $c a .2500 \mathrm{~m}$. The flags were used as test specimens to study the degradation of mechanical properties and morphological changes by ultraviolet ray and strong wind termed as "blizzard". All flags as the navigation were red color and the plain weave woven by nylon 6 fibers.

Table I shows the characteristics of the flags. Each flag was fastened to the bamboo pole and by a string and a small side part, which was parallel to the pole, of the flag wound around the pole was covered by tape to fix tightly, as shown in Figure 2. The initial height of lower part of flag was $c a .2 \mathrm{~m}$ above the snow surface to observe snow coverage. The flags exposed on the route did not remain the prototype because of violent weathering. The color fading was evaluated on 

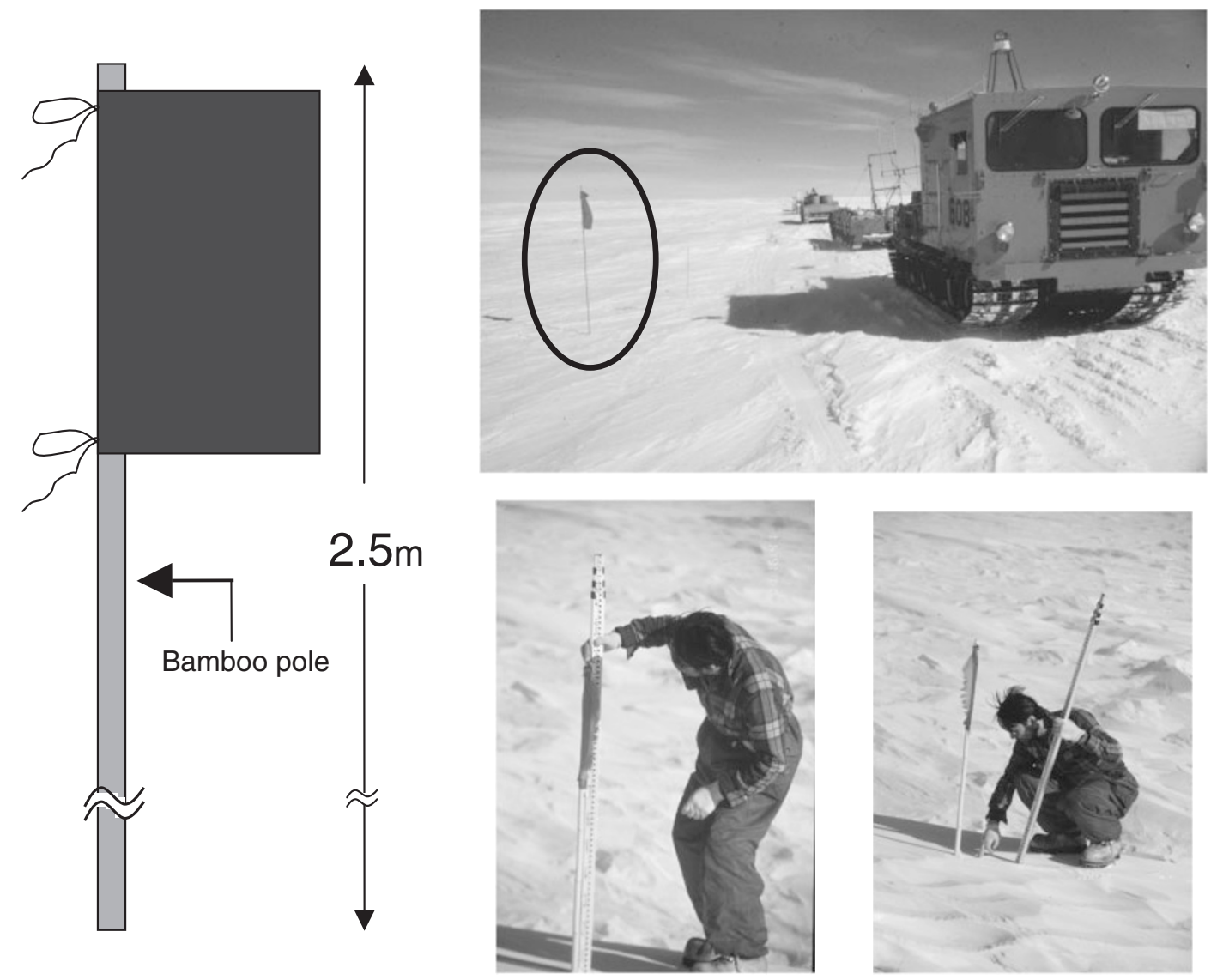

Figure 2. A flag as the ground mark set on the route.

Table I. Characteristics of the route flags

\begin{tabular}{ll}
\hline Size of flag & $21.5 \mathrm{~cm} \times 45.5 \mathrm{~cm}$ \\
Fiber & Nylon $6100 \%$ \\
Weave & Plain weave \\
Fabric density & Warp $49 / \mathrm{cm}$ \\
& Weft $35 / \mathrm{cm}$ \\
Size of fiber & Warp 89 dtex \\
& Weft 83 dtex \\
Thickness & $120 \mu \mathrm{m}$ \\
Color & Red \\
\hline
\end{tabular}

the basis of apparent depth of shade $(K / S)$ by using Kubelka-Munk equation: ${ }^{21} \quad K / S=(1-R)^{2} / 2 R$, where $R$ is the reflectance of monochromatic light at $540 \mathrm{~nm}$ from an infinitely thick pad of material, $K$ is the absorption coefficient of the material, and $S$ is the scattering coefficient. The value of $R$ was measured by using UV-260 (Shimadzu, P/N204-03900). The surface was analyzed by scanning electron microscope (Hitachi, SEM model S-310) and ESCA (Shimadzu, ESCA-850).

The degree of crystallinity was determined at $25^{\circ} \mathrm{C}$ by density measurement using a density gradient column with benzene and nitrobenzene as a medium. ${ }^{22}$

\section{RESULTS AND DISCUSSION}

Figure 3 shows some examples for the change in shape of the flags exposed on the route. The flags tore did not remain the prototype and showed drastic color fading. It may be expected that the wear and tear were due to "blizzard" and the color fading was attributed to violent irradiation of ultraviolet ray and strong multiplex reflection of sunshine from a snow surface. ${ }^{23}$ The violent disruption of the prototype was more progressive with increasing the altitude, since "blizzard" becomes stronger with increasing the altitude. Incidentally, the similar color fading was also observed for the flags exposed in out-door at Nishinomiya City of Japan with mild climate, but the tearing was less pronounced.

Figure 4 shows SEM photographs of the nylon 6 fibers extracted from the flags left on the rout. The sampling was done for the flags exposed on the routes at different sea levels to study the degradation of the fibers as a function of the altitude. The photographs revealed that the original fiber with a circular cross section shows a flat and smooth surface, while the fibers after the exposure show a weave-like shape by the disappearance of the surface (skin) parts. The shapes were almost independent of the altitude. The 


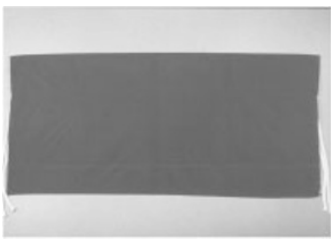

Original

A

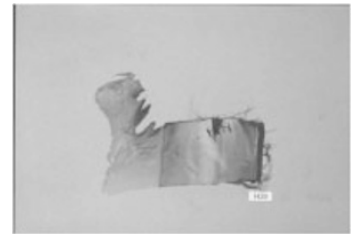

A-1

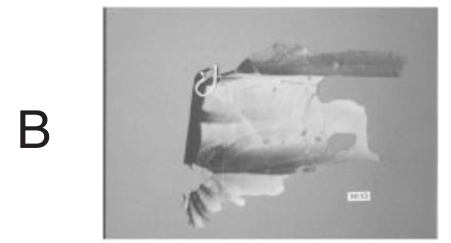

B-1

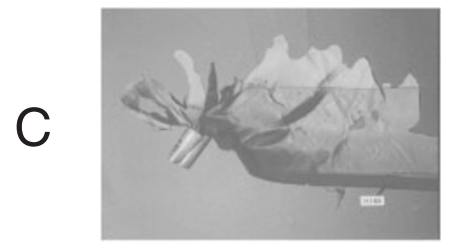

C-1

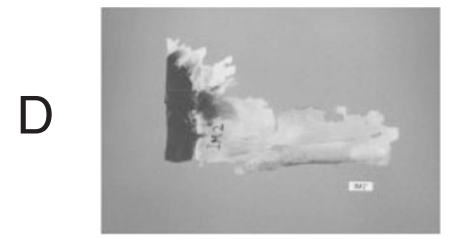

D-1

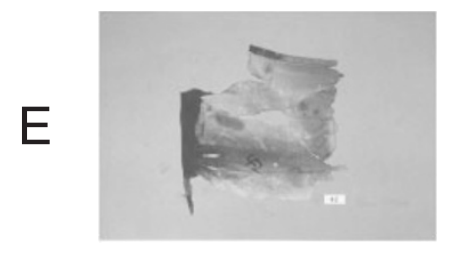

E-1

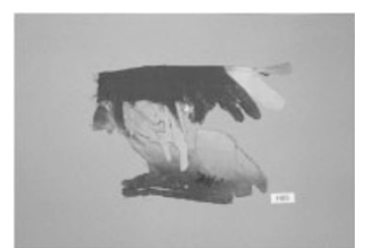

A-2

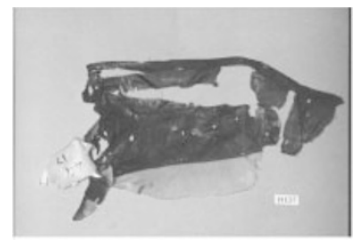

B-2

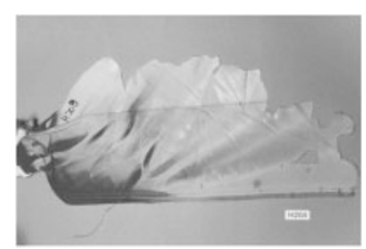

C-2

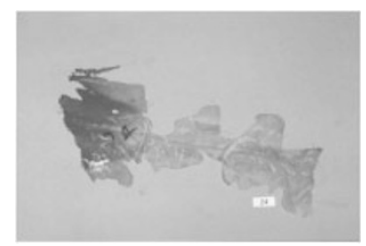

D-2

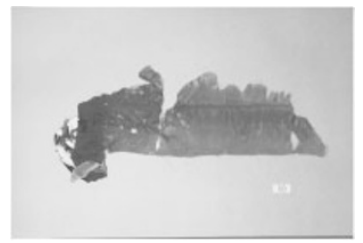

E-2

Figure 3. Examples for the change in shape of the flags exposed on the route for one year. A: Altitude of 950-1,200 m, B: Altitude of 1,300-1,400 m, C: Altitude of 1,500-1,650 m, D: Altitude of 2,100-2,300 m, E: Altitude of 2,350-2,500 m.

weave-like shape was thought to be attributed to the repetition of two mechanisms, the occurrence of the cracks as the degradation due to the polymer chain scission by ultraviolet rays and the tearing of the crack parts by "blizzard". The diameter of the original fiber is $c a .28 \mu \mathrm{m}$ and the average depth of the valleys is 2.6-5.3 $\mu \mathrm{m}$, which indicated $c a$. 10-20\% loss of the fibers.

In Figure 5, it may be noted that when the fibers were set in outdoor at Nishinomiya City with mild climate, the cross section of the fibers was maintained almost a circular shape in spite of the appearance of a number of cracks. Because of the appearance of the cracks, the influence of the ultraviolet rays on nylon 6 fibers at Nishinomiya City is expected to be almost the same as that at the Antarctic but the circular shape is maintained because of mild winds. The cracks are also observed for the fibers in the flag exposed for 


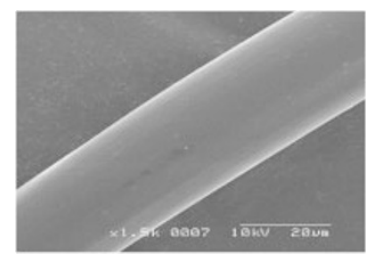

Original

A

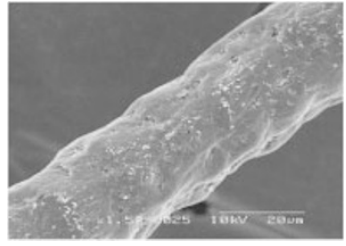

A-1

B

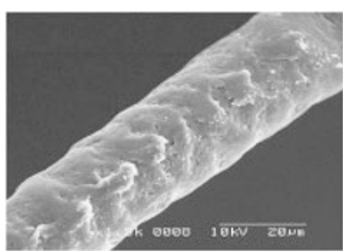

B-1

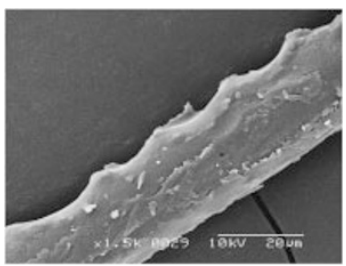

C-1

D

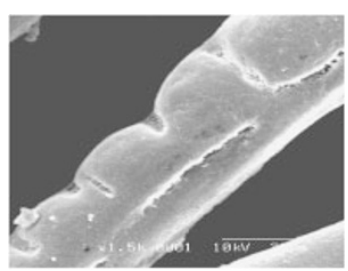

D-1

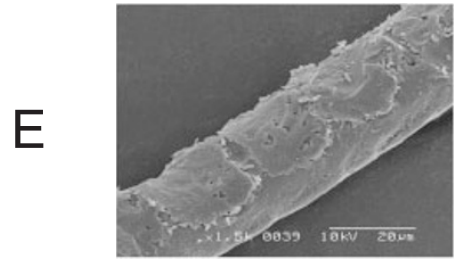

$\mathrm{E}-1$

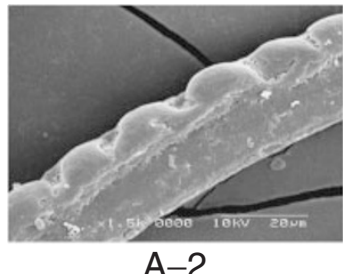

A-2

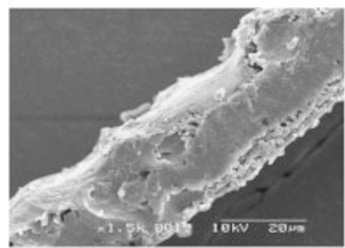

B-2

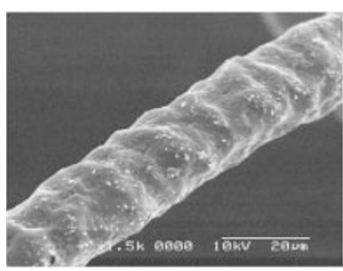

C-2

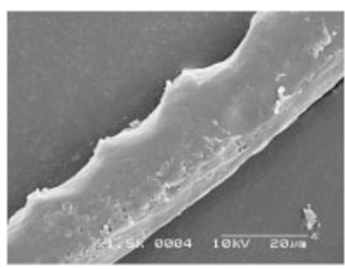

D-2

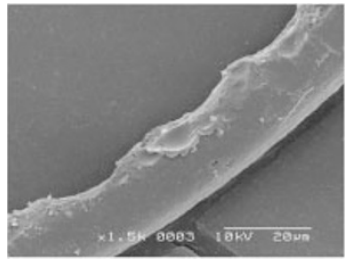

E-2

Figure 4. SEM photographs of the flags exposed in the Antarctic. A: Altitude of 950-1,200 m, B: Altitude of 1,300-1,400 m, C: Altitude of 1,500-1,650m, D: Altitude of 2,100-2,300 m, E: Altitude of 2,350-2,500 m.

$62 \mathrm{~d}$ in summer season under violent climate at the foot of south-west wall (close to the end of ice-fall) at Mt. Everest, the altitude being $c a .5350 \mathrm{~m}$. The tearing of the skin parts of the fibers, however, is not observed, although the flags were torn without remaining the prototype as the flags exposed on the route in the Antarctic shown in Figure 3. Judging from such strong winds at Mt. Everest as "blizzard" at Antarctic, it may be expected that ultraviolet rays in Himalayas is less serious than that in Antarctic, and then the fibers in the disrupted flag did not show a wave-like shape by tearing skin parts. Unfortunately, it is impossible to estimate the quantity of ultraviolet rays in $\mathrm{Hi}-$ malayas, since steep mountains hampers to set a base 


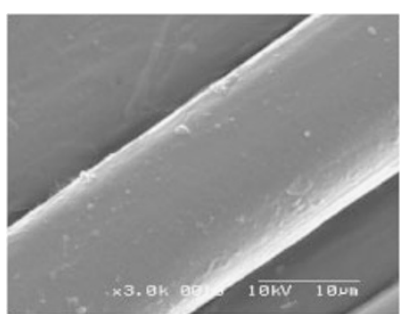

a

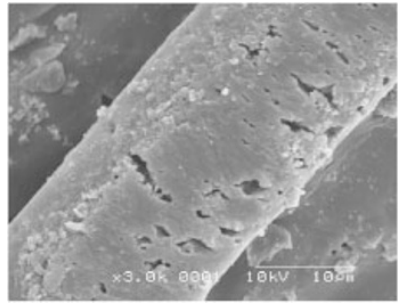

b

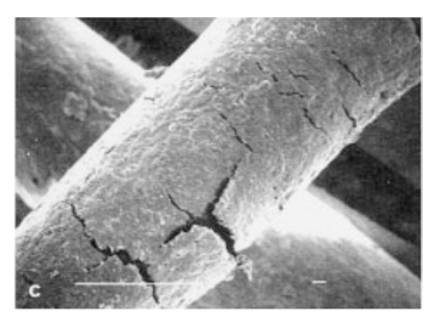

C

Figure 5. SEM photographs of the nylon 6 fiber after exposure. a: Original, b: Nishinomiya City, c: Mt. Everest (Altitude 5,350 m).

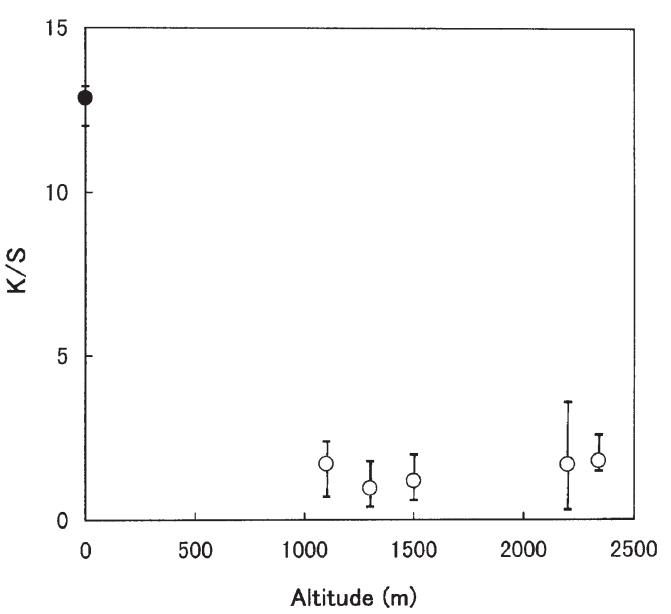

Figure 6. Apparent depth of shade in the flags against the altitude of the setting route of the flags. ( $\bullet$ : Original, $\bigcirc$ : After exposure)

camp for long time.

Figure 6 shows the refractive index of the flags against the altitude of the setting route of the flags in the Antarctic. The color fading of the flags is very serious in comparison with that of the original flag. This result is in good relationship with the disruption and color fading of flags in Figures 3 as well as the difference of the skin part in Figures 4 and 5.

Figure 7 shows the comparison of load-strain curves of the flags exposed at outside in Antarctic and at Nishinomiya City. The load is normalized by the length of the fabric clamped in the instrument. This is due to the fact that the cross section area of the flag cannot be estimated for fabrics. The normalization by the length is a well-known method, ${ }^{24}$ which has been used to estimate mechanical properties of fabrics. The strength of the flags exposed at A block in the Antarctic (see Figure 1) decreases drastically in comparison with that of the original flag. However, the strength is slightly higher than that of the flag exposed in Nishinomiya City of Japan. Judging from the radius of fibers shown in Figures 4 and 5, it may be expected that the cross section area of the flag exposed at the Antarctic is thinner than that of the flag exposed at Nishinomiya City because of the strong winds,

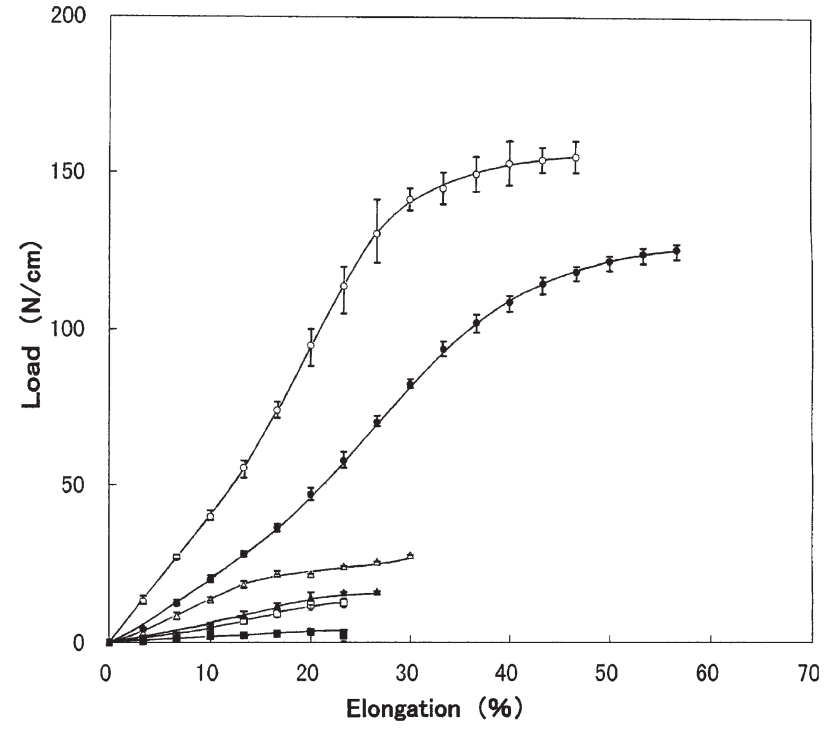

Figure 7. The load-strain curves of the flags exposed in the Antarctic and Nishinomiya City. Original ( $\bigcirc$ : warp, ๑: weft), Exposed in the Antarctic ( $\triangle$ : warp, $\boldsymbol{\Delta}$ : weft) Exposed in Nishinomiya City ( $\square$ : warp, $\square$ : weft).

while the core (inner) part of the fibers did not sustain serious damage by the violent irradiation of the ultraviolet ray as discussed before.

The quantitative analysis of the fiber surface was done by using ESCA measurements. Figure 8 shows a peak for $\mathrm{C}_{1 \mathrm{~s}}$ measured for the fibers in the flags set on the route in the Antarctic as well as at Nishinomiya City, in addition to the original flag, in which, of course, the correction of photo-ionizatiion cross section was done. Based on the established analysis, ${ }^{25}$ the peak was classified into four components, in which peak 1, peak 3 and peak 4 are from the contributions due to $\mathrm{CH}_{2}-\mathrm{CH}_{2},-\mathrm{C}-\mathrm{N}$ and $>\mathrm{C}=\mathrm{O}$ groups, respectively, in nylon 6 structural unit. The peak 2 is probably attributed to $>\dot{\mathrm{C}}-\mathrm{OH}$ due to oxidation of the fibers. The total peak area of peak 2 and peak 4 against the whole peak area calculated for the fiber surface of the flags exposed in out-door at the Antarctic and Nishinomiya City are listed as the ratio (\%) in Table II. For the fibers of exposed flags, the value becomes larger as oxidation reaction becomes more ac- 


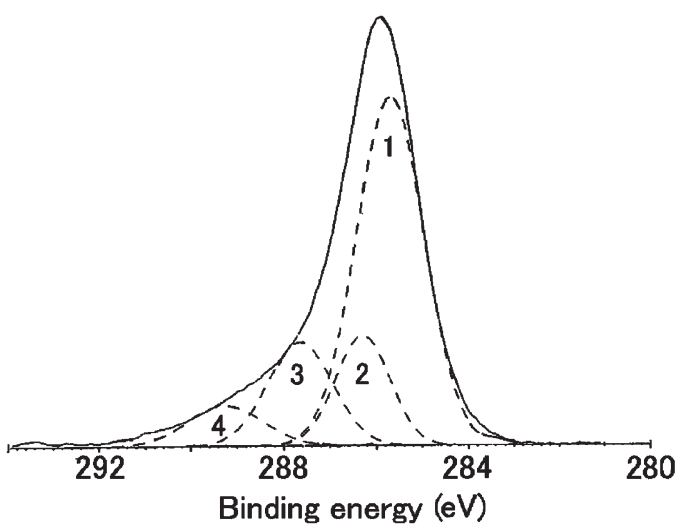

(a)

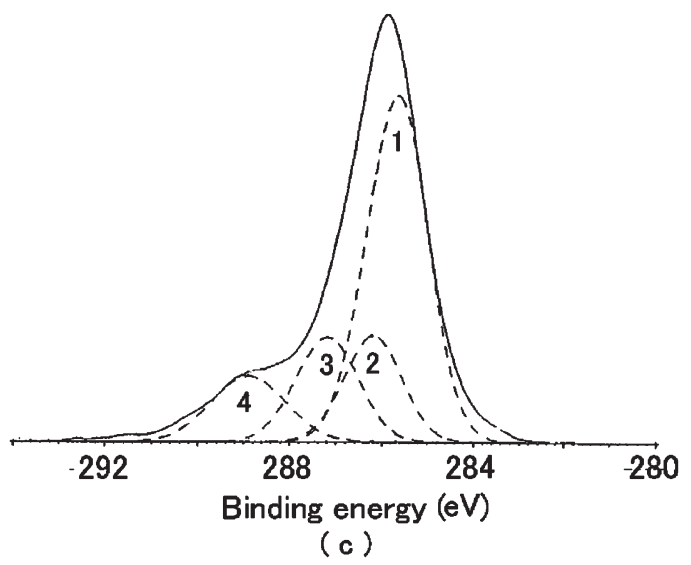

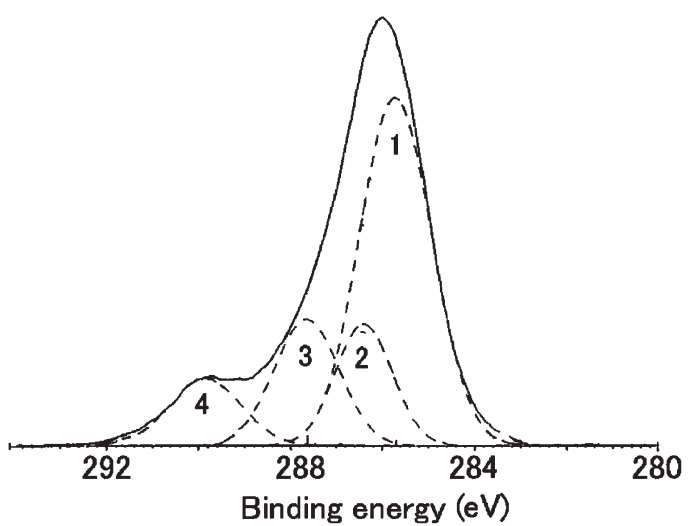

(b)

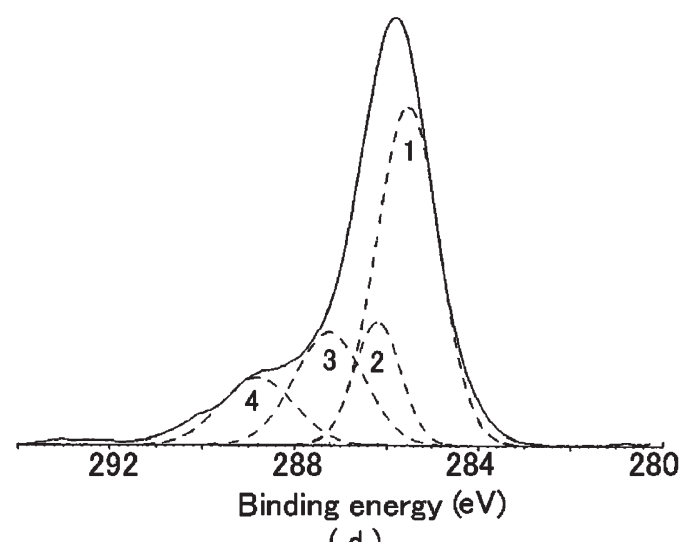

(d)

Figure 8. $\mathrm{C}_{1 \mathrm{~s}}$ spectra by ESCA measurements of the flags exposed in the Antarctic and Nishinomiya City. Each peak was classified into four components which were represented by dotted lines. (a) Original, (b) Exposed in Nishinomiya City (200 d), (c) Exposed in the Antarctic (A block), (d) Exposed in the Antarctic (C block).

Table II. The total peak area of peak 2 and peak 4 against the whole peak area; (peak $2+$ peak 4 )/whole peak

\begin{tabular}{llc}
\hline \multicolumn{2}{c}{ Exposed place } & $\begin{array}{c}\text { Peack area ratio } \\
(\%)\end{array}$ \\
\hline Original & & 23.0 \\
Antarctica & A block & 28.6 \\
& C block & 27.0 \\
& E block & 26.2 \\
Nisinomiya City & & \\
Exposure & $112 \mathrm{~d}$ & 24.0 \\
& $200 \mathrm{~d}$ & 26.0 \\
\hline
\end{tabular}

tive by sunshine in out-door. Of course, this tendency becomes more pronounced at higher sea level at the Antarctic.

Table III shows the change in crystallinity measured for the fibers in the flags exposed in out-door at the Antarctic and Nishinomiya City. The exposed periods chosen at Nishinomiya City were 112 and $200 \mathrm{~d}$, which is shorter than the half period at the Antarctic. This is due to the fact that sunshine days at the Antarctic is $c a$. half of a year. The crystallinity increases as the altitude at the Antarctic becomes high-
Table III. Change of the degree of crystallization of the flags exposed in the Antarctic and Nisinomiya City

\begin{tabular}{llc}
\hline \multicolumn{2}{c}{ Exposed place } & $\begin{array}{c}\text { Crystallinity } \\
(\%)\end{array}$ \\
\hline Original & & 35.1 \\
Antarctica & A block & 39.7 \\
& C block & 40.7 \\
Nisinomiya City & E block & 43.0 \\
Exposure & & \\
& $112 \mathrm{~d}$ & 44.9 \\
& $200 \mathrm{~d}$ & 45.3 \\
\hline
\end{tabular}

er. However, the crystallinity of the flags exposed at Nishinomiya City is higher than the highest value in the Antarctic at E block. This is due to disappearance of the skin part of the fiber in the flag exposed in the Antarctic but due to less progression of chain scission in the core part of the fiber. Because the increase in crystallinity was confirmed to be due to the fact that chain scission occurs mainly in the amorphous regions and the molecular relaxation of chains by chain scission enhances coagulation of the molecules. ${ }^{26,27}$ This phenomenon is quite different from the chain scission 
of polyethylene by electron irradiation, as has been reported that the chain scission occurred in crystallites and the cross-linking occurred in amorphous parts. ${ }^{28,29}$

According to the reports for climate of Antarctic, ${ }^{30,31}$ the irradiation quantity of ultraviolet rays increases year by year. The UV-A with wavelength of 315-400 nm, becomes maximum from December to January, while UV-B with wavelength $280-315 \mathrm{~nm}$, which is injurious, on the beginning of December. The average irradiation at the Antarctic is about twice as the quantity at Nishinomiya City, although the data at Nishinomiya City were scattered and the average value was adopted. Incidentally, the credibility of the quantitative data of the irradiation observed at the Antarctic is very high, since clouds do not appear generally and the observation is very easy.

A series of experimental results provides that the surface of nylon 6 fiber in the flag exposed on the route in the Antarctic suffered serious damage by very strong ultraviolet rays and multiplex reflection of sunshine from the snow surface. The surface degradation of fibers in the flags and the color fading of the flags exposed in the Antarctic is only warning for modern utilitarian development of industries, and then the future view for earth circumstance must be taken into consideration.

\section{CONCLUSIONS}

The surface of the fiber exposed on the route from Syowa Station and Dome Fuji in the Antarctic became an irregular shape by the disappearance of the surface (skin) parts. The disappearance was attributed to the occurrence of cracks by ultraviolet ray irradiation and the tearing of the cracking parts by "blizzard". Such disappearance could not be observed for the fibers in the flag exposed at out-door of Nishinomiya City with mild climate.

\section{REFERENCES}

1. T. Yasuda, Sen-i Gakkaishi, 17, 702 (1961).

2. T. Yasuda, K. Hirai, and M. Okuno, Bull. Mukogawa Women's Univ., 11, S47 (1963).

3. T. Yasuda, Sen-i Gakkaishi, 15, 228 (1959).

4. T. Yasuda and K. Yamashina, Bull. Mukogawa Women's Univ., 18, S71 (1970).
5. T. Yasuda and T. Okuno, Bull. Mukogawa Women's Univ., 29, 1 (1981).

6. Y. Fujiwara, S. Kobayashi, and T. Yasuda, Sen-i Gakkaishi, 30, T434 (1974).

7. Y. Fujiwara and S. Kobayashi, Kobunshi Ronbunshu, 33, 711 (1976).

8. E. Ikeda, J. Photopolym. Sci. Technol., 8, 109 (1995).

9. M. Ajioka, Sen-i Gakkaishi, 52, 232 (1996).

10. J. Pabiot and J. Verdu, Polym. Eng. Sci., 21, 32 (1981).

11. P. Blais, D. J. Carlsson, and D. M. Wiles, J. Polym. Sci., Part A-1: Polym. Chem., 10, 1077 (1972).

12. A. V. Challoner, D. Corless, A. Davis, G. H. Deane, B. L. Diffey, S. P. Gupta, and I. A. Magnus, Clin. Exp. Dermatol., 1, 175 (1976).

13. J. F. Leach, V. E. McLeod, A. R. Pingstone, A. Davis, and G. H. Deane, Clin. Exp. Dermatol., 3, 77 (1978).

14. H. Moseley, B. L. Diffey, J. M. Marks, and R. M. Mackie, Br. J. Dermatol., 105, 573 (1981).

15. C. D. Holman, I. M. Gibson, M. Stephenson, and B. K. Armstrong, Clin. Exp. Dermatol., 8, 269 (1983).

16. O. Larko and B. L. Diffey, Clin. Exp. Dermatol., 8, 279 (1983).

17. F. S. Rosenthal, C. Phoon, A. E. Bakalian, and H. R. Taylor, Invest. Optalmol Vis. Sci., 29, 649 (1988).

18. F. S. Rosenthal, R. A. Lew, L. J. Rouleau, and M. Thomson, Photodermatol. Photoimmunol. Photomed., 7, 77 (1990).

19. S. K. Melville, F. S. Rosenthal, R. Luckmann, and R. A. Lew, Photodermatol. Photoimmunol. Photomed., 8, 99 (1991).

20. E. Herlihy, P. H. Gies, C. R. Roy, and M. Jones, Photochem. Photobiol., 60, 288 (1994).

21. P. Kubelka and F. Munk, Z. Tech. Phys., 12, 593 (1931).

22. U. Kinoshita, Bull. Toray, 9, 1 (1954).

23. K. Endo, K. Matue, S. Takeshita, T. Sskata, and M. Sasaki, J. Illum. Eng. Inst. Jpn., 82, 877 (1998).

24. T. Kawabata, J. Textile Mach. Soc. Jpn., 39, T169 (1986).

25. "High Resolution XPS of Organic Polymers, The Scienta ESCA 300 Database," G. Beamson and D. Briggs, Ed., John Wiley \& Sons, Chichester, U.K., 1992.

26. S. Lazara and R. Srinivasan, J. Phys. Chem., 90, 2124 (1986).

27. R. J. Morgan, J. Polym. Sci., Polym. Phys. Ed., 21, 1757 (1983).

28. S. H. Zeronian and M. S. Elloson, J. Appl. Polym. Sci., 24, 1497 (1979).

29. S. Yano and M. Murayama, Japan Rheology Gakkaishi, 7, 34 (1979).

30. S. Takeshita, H. Miyaoka, M. Ejiri, and M. Sasaki, Antarctic Rec., 45, 1 (2001).

31. K. Endo, K. Matsue, S. Takeshita, T. Sakata and M. Sasaki, J. Illum. Eng. Inst. Jpn., 82, 887 (1998). 